Christian Torgersen

Günter Luckner

Daniel C. H. Schröder

Christian A. Schmittinger

Christopher Rex

Hanno Ulmer

Martin W. Dünser

\title{
Concomitant arginine-vasopressin and hydrocortisone therapy in severe septic shock: association with mortality
}

Received: 3 January 2011

Accepted: 18 April 2011

Published online: 21 July 2011

(C) Copyright jointly held by Springer and ESICM 2011

None of the authors has a conflict of interest in regard to the drugs or methods discussed in this manuscript.

This article is discussed in an editorial available at: doi:

10.1007/s00134-011-2313-2.

\section{Electronic supplementary material} The online version of this article (doi:10.1007/s00134-011-2312-3) contains supplementary material, which is available to authorized users.

C. Torgersen $(\bowtie) \cdot$ C. A. Schmittinger Department of Intensive Care Medicine, Inselspital, Bern Medical University, Freiburgstrasse 18, 3010 Bern, Switzerland e-mail: Christian-Erik.Torgersen@insel.ch Tel.: +41-31-6322111

G. Luckner - D. C. H. Schröder Department of Anaesthesiology and Intensive Care Medicine, Innsbruck Medical University, Innsbruck, Austria

C. Rex

Department of Anaesthesiology and Intensive Care Medicine, Kreiskliniken Reutlingen, Reutlingen, Germany

\section{H. Ulmer}

Department of Medical Statistics, Informatics and Health Economics, Innsbruck Medical University, Innsbruck, Austria
M. W. Dünser

Department of Anaesthesiology and Intensive Care Medicine, Salzburg General Hospital and Paracelsus Private Medical University, Salzburg, Austria

Abstract Purpose: To evaluate the association between concomitant arginine-vasopressin (AVP)/hydrocortisone therapy and mortality in severe septic shock patients. Methods: This retrospective study included severe septic shock patients treated with supplementary AVP. To test the association between concomitant AVP/hydrocortisone use and mortality, a multivariate regression and Cox model (adjusted for admission year, initial AVP dosage and the Sepsis-related Organ Failure Assessment score before AVP) as well as a propensity score-based analysis were used. In both models, intensive care unit (ICU) and 28-day mortality served as outcome variables. Results: One hundred fifty-nine patients were included. Hydrocortisone was administered to $76(47.8 \%)$ at a median daily dosage of 300 (200-300) mg. In the multivariate logistic regression model, concomitant use of AVP and hydrocortisone was associated with a trend towards lower ICU (OR, 0.51; CI 95\%, $0.24-1.08 ; p=0.08)$ and 28-day (HR, 0.69; CI 95\%, 0.43-1.08; $p=0.11)$ mortality. The probability of survival at day 28 , as predicted by the regression model, was significantly higher in patients treated with concomitant AVP and hydrocortisone compared to those receiving AVP without hydrocortisone $(p=0.001)$. In a propensity score-based analysis, ICU (45 vs. 65\%; OR, 0.69; CI 95\% $0.38-1.26 ; p=0.23)$ and 28 -day mortality ( 35.5 vs. $55 \%$; OR, 0.59 ; CI $95 \%, 0.27-1.29 ; p=0.18$ ) was not different between patients treated with $(n=40)$ or without concomitant hydrocortisone $(n=40)$. Conclusion: Concomitant AVP and hydrocortisone therapy may be associated with a survival benefit in septic shock. An adequately powered, randomised controlled trial appears warranted to confirm these preliminary, hypothesis-generating results.

Keywords Arginine-vasopressin . Hydrocortisone - Septic shock · Mortality 


\section{Introduction}

Addition of the neurohypophyseal hormone argininevasopressin (AVP) to catecholamine vasopressors in patients with septic shock can restore tissue perfusion pressure [1], reduce norepinephrine requirements [1], improve kidney function [2], and decrease the incidence of catecholamine-associated adverse side effects [3]. In a multicenter trial, supplementary AVP improved 28- and 90-day mortality in patients requiring $5-14 \mu \mathrm{g} / \mathrm{min}$ of norepinephrine before the start of AVP, but not in patients in need of higher norepinephrine dosages [4]. The latest evidence suggests that concomitant use of arginine vasopressin (AVP) and hydrocortisone may have beneficial effects on septic shock survival $[5,6]$.

In this study, the association between concomitant AVP and hydrocortisone therapy with mortality was evaluated in a cohort of 159 patients suffering from severe septic shock. We hypothesised that patients treated with concomitant AVP and hydrocortisone had a lower mortality than patients receiving AVP without hydrocortisone.

\section{Materials and methods}

This analysis was designed as a retrospective cohort study. The study protocol was approved by the Ethics Committee of the Innsbruck Medical University, Innsbruck/Austria (UN3671). From 1999 until 2008, the medical charts of a 12-bed general and surgical intensive care unit at a tertiary university teaching hospital were reviewed for patients who fulfilled the following inclusion criteria: (1) presence of septic shock as defined by the 1992 ACCP/SCCM consensus conference [7] and (2) treatment with supplementary AVP. Age $<18$ years, pregnancy, chronic pathologies of the hypothalamic-pituitary-adrenal axis, chronic corticosteroid therapy, duration of AVP infusion $<6 \mathrm{~h}$, and AVP therapy for other indications than sepsis related-cardiovascular failure were exclusion criteria. Some patients included in this study have been analysed in previous publications of our working group $[1,3,8,9]$.

\section{Haemodynamic management}

All patients were treated according to an institutional haemodynamic protocol that served as a treatment guideline [9]. Patients were routinely monitored with an arterial and central venous line. A pulmonary artery or trans-pulmonary thermodilution catheter was inserted at the discretion of the attending physician. Fluid resuscitation was conducted according to the response of cardiac filling pressures, stroke volume/cardiac index, and/or arterial blood pressure to repetitive volume loading using gelatine-based colloids or crystalloid solutions. If the cardiac index remained $<2-2.51 / \mathrm{min} / \mathrm{m}^{2}$ and/or mixed/ central venous oxygen saturation $<60-65 \%$ despite fluid resuscitation and blood transfusions, milrinone and/or epinephrine was continuously infused. Norepinephrine was infused to increase mean arterial blood pressure $>60-70 \mathrm{mmHg}$. A supplementary AVP infusion at a fixed dosage of 1-6 IU/h was added when the targeted mean arterial blood pressure level could not be achieved despite norepinephrine dosages exceeding $0.5 \mu \mathrm{g} / \mathrm{kg} / \mathrm{min}$ or catecholamine-induced side effects had occurred. No patient received AVP as the sole vasopressor agent. Continuous veno-venous haemofiltration was employed for renal indications only. Except for the use of milrinone and/or epinephrine as the first line inotrope, causative and supportive sepsis therapy was performed in line with the 2004 and 2008 Surviving Sepsis Campaign guidelines $[10,11]$. Activated protein $\mathrm{C}$ was not administered in any patient.

An ACTH test was not routinely performed, and hydrocortisone was administered at the discretion of the attending physician based on individual patient factors, norepinephrine requirements, and contemporary scientific evidence. If hydrocortisone was prescribed it was administered as a continuous infusion at daily dosages ranging between 100 and $300 \mathrm{mg}$. Hydrocortisone was continued until catecholamine vasopressors could be withdrawn and was then slowly tapered off over several days.

\section{Data documentation}

The following data were extracted from medical records of all patients: age, gender, body mass index, year of ICU admission, infectious focus, the admission Simplified Acute Physiology Score II [12], need for surgery, need for continuous veno-venous haemofiltration, duration of shock (defined as the need for any vasopressor drug) following initiation of AVP therapy, length of intensive care unit stay, as well as intensive care unit and 28-day mortality. The Sepsis-related Organ Failure Assessment (SOFA) score [13] was calculated from the most aberrant haemodynamic, clinical, and laboratory variables before the start of AVP and during the intensive care unit stay. Hydrocortisone dosages as well as the time point of hydrocortisone implementation (before or after start of AVP infusion) were documented.

\section{Statistical analysis}

All statistical analyses were performed using the SPSS software package (SPSS Inc., Chicago, IL). Group differences in demographic and clinical variables, as well as mortality were assessed with the Mann-Whitney $U$ or Fisher's exact test, as applicable. To test the association between 
concomitant AVP and hydrocortisone use and mortality, two models were used: first, a multivariate logistic regression model and second a propensity score-based model.

Concomitant hydrocortisone therapy and variables differing between patients with or without concomitant hydrocortisone therapy were included as independent covariates into the multivariate regression model. Unadjusted group comparisons were performed for demographic, clinical, and haemodynamic and laboratory variables before start of AVP therapy. The Fisher's exact or Mann-Whitney $U$-rank sum test was used for group comparisons, as appropriate. Variables showing group differences at an $\alpha$-level $<0.1$ (year of admission and initial AVP dosage) or for which a biological effect was highly likely (age, SOFA score before start of AVP) were subsequently included into the multivariate logistic regression model to analyse the independent association between concomitant hydrocortisone use and intensive care unit mortality. For the analysis including 28-day mortality, the same independent variables were included into a Cox proportional hazard model accounting for the survival time until day 28. To investigate whether timing of hydrocortisone administration influenced the association between concomitant AVP and hydrocortisone therapy, addition of hydrocortisone before the start of AVP was added into the models as a binary variable. Kaplan-Meier curves were drawn to display and compare (log-rank test) the probability of cumulative 28-day survival based on the results of the Cox model. A linear regression model adjusted for age, admission year, initial AVP dosage, and SOFA score before the start of AVP was used to determine the association between concomitant hydrocortisone therapy (independent variable) and shock duration following the start of AVP (dependent variable) in study patients experiencing shock reversal.

A propensity score [14] was established using the following covariates: admission year, age, SOFA score before the start of AVP, norepinephrine dose before the start of AVP, and initial AVP dose. This score was then used to couple patients with concomitant hydrocortisone and AVP therapy as well as patients with supplementary AVP infusion but no concomitant hydrocortisone therapy. For the coupling process optimal 1:1 matching (4-1 digits) was used. No replacements for previously matched patients were allowed. Intensive care unit and 28-day mortality was then compared between the two patient groups (concomitant AVP and hydrocortisone therapy versus supplementary AVP infusion without concomitant hydrocortisone therapy) using a conditional logistic regression model for intensive care unit mortality and a Cox model stratified to matched pairs for 28-day mortality.

A significance level of $p<0.05$ was applied for all comparisons. Data are presented as median values with interquartile ranges (IQR), if not otherwise indicated.

\section{Results}

During the observation period, 159 septic shock patients who were treated with a supplementary AVP infusion fulfilled the inclusion criteria for this study (Table 1). Hydrocortisone was administered to 76 patients $(47.8 \%)$ at a median daily dosage of 300 (200-300) $\mathrm{mg}$. The year of admission differed significantly between groups and affected the study population's intensive care unit and 28-day mortality (Electronic Supplementary Material Fig. 1). Haemodynamic and laboratory variables before the start of AVP therapy are summarised in Table 2. In both groups, AVP was initiated at 4 (2-4) IU/h $(p=0.05)$. In 34 patients $(44.7 \%)$, hydrocortisone was initiated before and in 42 patients $(55.3 \%)$ after the start of AVP therapy.

In the multivariate logistic regression model (adjusted for admission year, initial AVP dosage and the SOFA score before start of AVP), concomitant use of AVP and hydrocortisone was associated with a trend towards lower 28-day and intensive care unit mortality (Table 3). The probability of survival at day 28 as predicted by the multivariate regression model was significantly higher in patients treated with AVP and hydrocortisone compared to those receiving supplementary AVP without concomitant hydrocortisone (Fig. 1). There was no difference in intensive care unit (OR, 0.71; CI 95\%, 0.27-1.88; $p=0.49$ ) or 28-day mortality (HR, 0.8; CI 95\%, $0.45-1.58 ; p=0.52$ ) between patients in whom concomitant hydrocortisone therapy was started before or after initiation of supplementary AVP. Concomitant hydrocortisone and AVP therapy was not associated with the duration of shock following the start of AVP therapy (standardised B-coefficient, $-0.1 ; p=0.52$ ).

Eighty of 159 study patients $(50 \%)$ could be included into the propensity score-based analysis (concomitant AVP and hydrocortisone therapy, $n=40$; supplementary AVP therapy without concomitant hydrocortisone therapy, $n=40$ ). The number of patients coupled on $4,3,2$, and 1 digits of the propensity score was $2(2.5 \%), 14$ $(17.5 \%), 48(60 \%)$, and $16(20 \%)$, respectively. In the propensity score-based analysis, intensive care unit (45 vs. $65 \%$; OR, 0.69; CI 95\% 0.38-1.26; $p=0.23)$, and 28-day mortality (35.5 vs. 55\%; HR, 0.59; CI 95\%, $0.27-1.29 ; p=0.18$ ) was not different between patients treated with or without concomitant hydrocortisone.

\section{Discussion}

The results of this retrospective cohort study suggest that concomitant use of AVP and hydrocortisone could be associated with a survival benefit in septic shock patients. This association was not affected by the timing of hydrocortisone administration in relation to initiation of 
Table 1 Characteristics of study patients

\begin{tabular}{|c|c|c|c|}
\hline & $\mathrm{AVP}+\mathrm{HC}$ & AVP & $p$-value \\
\hline$n$ & 76 & 83 & \\
\hline Age (years) & $69(57-78)$ & $66(57-75)$ & 0.2 \\
\hline Male sex $n(\%)$ & $47(61.8)$ & $55(66.3)$ & 0.62 \\
\hline BMI $\left(\mathrm{kg} / \mathrm{m}^{2}\right)$ & $25(22-27)$ & $26(23-30)$ & 0.33 \\
\hline Admission year & $2004(2002-2006)$ & $2001(2000-2004)$ & $<0.001^{\mathrm{b}}$ \\
\hline Infectious focus $n(\%)$ & & & 0.5 \\
\hline Abdominal & $39(51.3)$ & $32(38.6)$ & \\
\hline Pulmonary & $17(22.4)$ & $26(31.3)$ & \\
\hline Wound/soft tissue & $5(6.6)$ & $9(10.8)$ & \\
\hline Urogenital & $3(3.9)$ & $2(2.4)$ & \\
\hline Catheter & $2(2.6)$ & $1(1.2)$ & \\
\hline Others & $10(13.2)$ & $13(15.7)$ & \\
\hline Admission SAPS II (pts) & $52(42-63)$ & $50(39-63)$ & 0.61 \\
\hline Need for surgery $n(\%)$ & $55(72.4)$ & $62(74.7)$ & 0.86 \\
\hline Need for CVVHF $n(\%)$ & $46(60.5)$ & $53(63.9)$ & 0.74 \\
\hline NE dose before AVP $(\mu / \mathrm{kg} / \mathrm{min})$ & $0.66(0.39-1.19)$ & $0.8(0.42-1.25)$ & 0.22 \\
\hline SOFA score preAVP (pts) & $15(13-16)$ & $15(13-17)$ & 0.34 \\
\hline Initial AVP dose $1 \mathrm{U} / \mathrm{h}$ & $4(2-4)$ & $4(2-4)$ & 0.05 \\
\hline Max SOFA score (pts) & $15(13-17)$ & $16(14-18)$ & 0.25 \\
\hline Shock duration $^{\mathrm{a}}(\mathrm{h})$ & $142(100-257)$ & $173(104-300)$ & 0.59 \\
\hline Length of ICU stay (days) & $17(5-30)$ & $14(6-26)$ & 0.4 \\
\hline 28-day mortality $n(\%)$ & $36(47.4)$ & $51(61.4)$ & 0.08 \\
\hline ICU mortality $n(\%)$ & $40(52.6)$ & $57(68.7)$ & 0.05 \\
\hline
\end{tabular}

Data are presented as median values with interquartile ranges, if not otherwise indicated

$A V P+H C$ combined arginine vasopressin and hydrocortisone therapy, $A V P$ arginine vasopressin, $B M I$ body mass index, $S A P S$ Simplified Acute Physiology Score, NE norepinephrine, SOFA Sequential Organ Failure Assessment, preAVP before the start of arginine vasopressin infusion, SAPS Simplified Acute Physiology Score, $C V V H F$ continuous veno-venous haemofiltration, ICU intensive care unit

a After the start of AVP (only intensive care unit survivors included)

b Significant difference between groups

Table 2 Haemodynamic and laboratory variables before the start of AVP

\begin{tabular}{llll}
\hline & AVP + HC & AVP & $p$-value \\
\hline$n$ & 76 & 83 & $110(98-125)$ \\
Heart rate $(\mathrm{bpm})$ & $110(100-120)$ & $60(50-65)$ & 1 \\
MAP $(\mathrm{mmHg})$ & $55(50-65)$ & $13(11.5-16)$ & 0.61 \\
$\mathrm{CVP}(\mathrm{mmHg})$ & $13(11-15)$ & $0.8(0.42-1.25)$ & 0.27 \\
NE dose $(\mu \mathrm{g} / \mathrm{kg} / \mathrm{min})$ & $0.66(0.39-1.19)$ & $0.43(0.25-0.6)$ & 0.22 \\
Milrinone dose $(\mu \mathrm{g} / \mathrm{kg} / \mathrm{min})$ & $0.4(0.25-0.57)$ & $7.31(7.24-7.38)$ & 0.27 \\
$\mathrm{pH}$ & $7.29(7.23-7.38)$ & $-3.9(-8$ to -0.7$)$ & 0.9 \\
Base deficit $(\mathrm{mmol} / \mathrm{l})$ & $-4.7(-7.6$ to -0.4$)$ & $39(18-68)$ & 0.89 \\
Lactate $(\mathrm{mg} / \mathrm{dl})$ & $35(19-59)$ & $15(13-17)$ & 0.34 \\
SOFA score $(\mathrm{pts})$ & $15(13-16)$ & \\
\hline
\end{tabular}

Data are presented as median values with interquartile ranges, if not otherwise indicated

$A V P+H C$ combined arginine vasopressin and hydrocortisone therapy, $A V P$ arginine vasopressin, MAP mean arterial blood

AVP therapy. Our findings are in line with the results of two recent studies in septic shock patients reporting a potential benefit of concomitant AVP and hydrocortisone therapy $[5,6]$. In a post-hoc analysis of the multicentre VASST study, Russell et al. [5] detected a significant interaction between AVP and hydrocortisone therapy, as well as a mortality benefit in corticosteroid-treated septic shock patients who received AVP compared to those treated with corticosteroids and norepinephrine alone. pressure, $C V P$ central venous pressure, $C I$ cardiac index, $S V R$ systemic vascular resistance, $N E$ norepinephrine, $S O F A$ Sequential Organ Failure Assessment

In contrast to our analysis, corticosteroids other than hydrocortisone were administered in the VASST study [5]. Furthermore, patients analysed in our study consistently suffered from severe septic shock and may therefore not be comparable to the VASST population in which a survival benefit for AVP was observed only in patients with less but not those with more severe septic shock. In a retrospective, case control study, more patients receiving concomitant AVP and hydrocortisone 
Table 3 Multivariate regression model to predict ICU and 28-day mortality

\begin{tabular}{|c|c|c|c|c|c|c|}
\hline & Variable type & Unit & Wald & Odds ratio & $95 \% \mathrm{CI}$ & $p$-value \\
\hline \multicolumn{7}{|l|}{ ICU mortality } \\
\hline SOFA score before AVP & Continuous & Per point & 9.28 & 1.24 & $1.08-1.43$ & 0.002 \\
\hline Concomitant $\mathrm{HC}$ therapy & Categorical & & 3.09 & 0.51 & $0.24-1.08$ & 0.08 \\
\hline Age & Continuous & Per year & 2.43 & 1.02 & $0.99-1.05$ & 0.12 \\
\hline Admission year & Categorical & & 0.38 & 1.05 & $0.91-1.2$ & 0.54 \\
\hline Initial AVP dosage & Continuous & Per IU/h & 0.37 & 1.09 & $0.82-1.45$ & 0.54 \\
\hline 28-day mortality & & & & Hazard ratio & & \\
\hline SOFA score before AVP & Continuous & Per point & 6.89 & 1.13 & $1.03-1.24$ & 0.009 \\
\hline Age & Continuous & Per year & 6.02 & 1.02 & $1-1.04$ & 0.01 \\
\hline Concomitant $\mathrm{HC}$ therapy & Categorical & & 2.61 & 0.69 & $0.43-1.08$ & 0.11 \\
\hline Initial AVP dosage & Continuous & Per IU/h & 1.12 & 1.11 & $0.92-1.33$ & 0.29 \\
\hline Admission year & Categorical & & 0.75 & 1.04 & $0.95-1.14$ & 0.39 \\
\hline
\end{tabular}

$I C U$ intensive care unit, $C I$ confidence interval, SOFA Sequential Organ Failure Assessment Score, $H C$ hydrocortisone, AVP arginine vasopressin

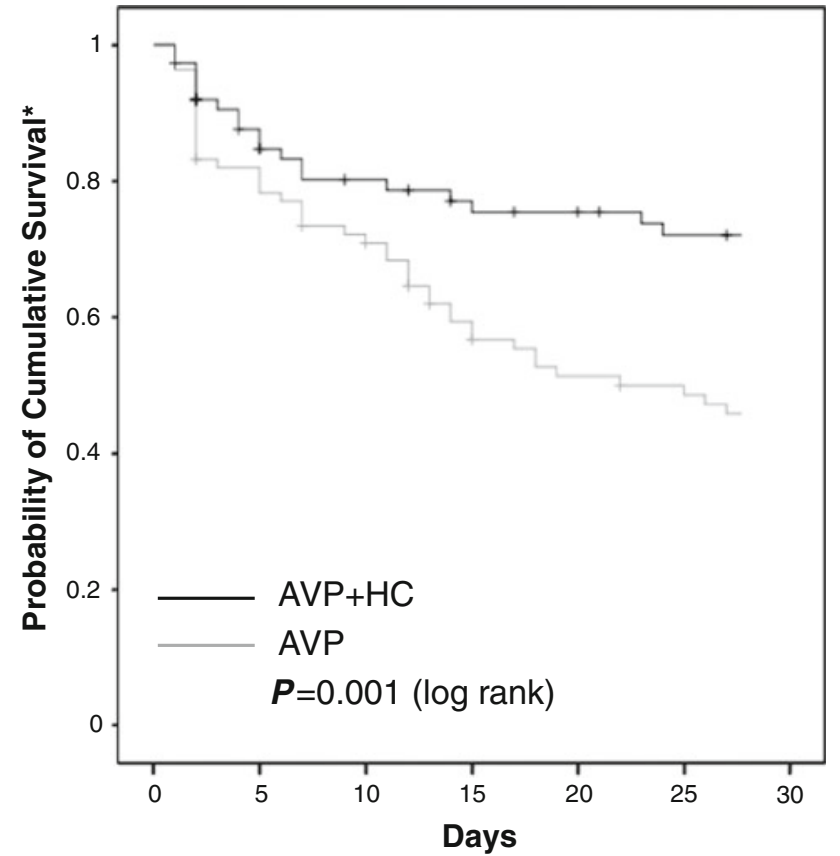

Fig. 1 Probability of cumulative 28-day survival as predicted by the adjusted logistic regression model for septic shock patients receiving arginine vasopressin with or without concomitant hydrocortisone. AVP arginine vasopressin, $H C$ hydrocortisone; *predicted by the logistic regression model adjusted for age, admission year, initial AVP dosage, and the Sepsis-related Organ Failure Assessment score before the start of AVP

were alive without vasopressor support at day 7 compared to subjects receiving AVP but no hydrocortisone [6].

Since this study included only patients treated with a supplementary AVP infusion, it is conceivable that a potential survival benefit of concomitant AVP and hydrocortisone therapy was attributable to hydrocortisone alone, thus occurring independently of the addition of AVP. More rapid shock reversal and better survival have been reported for hydrocortisone therapy in septic shock patients requiring escalating vasopressor dosages or those with an insufficient response to corticotropin [15, 16]. However, Russell et al. [5] observed that the probability of 28-day survival was higher in norepinephrine-treated septic shock patients receiving concomitant AVP and corticosteroids than in those receiving corticosteroids but no AVP. Several mechanisms could explain the beneficial effects of a concomitant AVP and hydrocortisone therapy in septic shock patients. These mechanisms potentially include multiple interactions between the hypothalamicpituitary-adrenal and hypothalamic-posterior pituitaryvasopressin axes [17-19] as well as restoration of vasopressinergic receptor sensitivity by corticosteroids [20].

Considering that our study included 159 septic shock patients, it was under-powered to investigate a mortality difference, and its results must be interpreted with caution. Furthermore, it needs to be remembered that although both a propensity score-based model and a multivariate regression/Cox model may identify independent associations between pre-defined variables, they cannot prove a causative relationship. Since patients treated with AVP but no hydrocortisone may not have survived long enough to receive hydrocortisone, heterogeneity in the timing of hydrocortisone administration could have further introduced a lead time bias into our analysis. This precludes conclusive comparisons of haemodynamic and laboratory variables between groups after initiation of AVP. Finally it needs to be acknowledged that this is a retrospective study implying the risk of missing data sets and undetected group differences at baseline. Since no management protocol was consistently adhered to in our study population but treatment was based on institutional guidelines, we cannot exclude that survival differences between groups arose from diverse patient managements. Finally, mortality rates were found to differ between admission years. Although all statistical analyses were adjusted for the year of admission, this cannot safely exclude the influence of all confounding 
factors related to changes occurring during the observation period.

In conclusion, concomitant AVP and hydrocortisone therapy may be associated with a survival benefit in septic shock. An adequately powered, randomised, controlled trial appears warranted to confirm these preliminary, hypothesis-generating results.

\section{References}

1. Luckner G, Dünser MW, Jochberger S, Mayr VD, Wenzel V, Ulmer H, Schmid S, Knotzer H, Pajk W, Hasibeder W, Mayr AJ, Friesenecker B (2005) Arginine vasopressin in 316 patients with advanced vasodilatory shock. Crit Care Med 33:2659-2666

2. Gordon AC, Russell JA, Walley KR, Singer J, Ayers D, Storms MM, Holmes CL, Hébert PC, Cooper DJ, Mehta S, Granton JT, Cook DJ, Presneill JJ (2010) The effects of vasopressin on acute kidney injury in septic shock. Intensive Care Med 36:83-91

3. Dünser MW, Mayr AJ, Ulmer H, Knotzer H, Sumann G, Pajk W, Friesenecker B, Hasibeder WR (2003) Arginine vasopressin in advanced vasodilatory shock: a prospective, randomized, controlled study. Circulation 107:2313-2319

4. Russell JA, Walley KR, Singer J, Gordon AC, Hébert PC, Cooper DJ, Holmes CL, Mehta S, Granton JT, Storms MM, Cook DJ, Presneill JJ, Ayers D, VASST Investigators (2008) Vasopressin versus norepinephrine infusion in patients with septic shock. N Engl J Med 358:877-887

5. Russell JA, Walley KR, Gordon AC, Cooper J, Hebert PC, Singer J, Holmes CL, Mehta S, Granton JT, Storms MM, Cook DJ, Presneill JJ, Ayers D, for the VASST investigators (2009) Interaction of vasopressin infusion, corticosteroid treatment, and mortality of septic shock. Crit Care Med 37:811-818

6. Bauer SR, Lam SW, Ch SS, Oyen LJ (2008) Effect of corticosteroids on arginine vasopressin-containing vasopressor therapy for septic shock: a case control study. J Crit Care 23:500-506

7. American College of Chest Physicians/ Society of Critical Care Medicine Consensus Conference (1992) Definitions for sepsis and organ failure and guidelines for the use of innovative therapies in sepsis. Crit Care Med 20:864-874
8. Luckner G, Mayr VD, Jochberger S, Wenzel V, Ulmer H, Hasibeder WR, Dünser MW (2007) Comparison of two dose regimens of arginine vasopressin in advanced vasodilatory shock. Crit Care Med 35:2280-2285

9. Torgersen C, Dünser MW, Wenzel V, Jochberger S, Mayr V, Schmittinger CA, Lorenz I, Schmid S, Westphal M, Grander W, Luckner G (2010) Comparing two different vasopressin doses in advanced vasodilatory shock: a randomized, controlled, open-label trial. Intensive Care Med 36:57-65

10. Dellinger RP, Carlet JM, Masur H, Gerlach H, Calandra T, Cohen J, GeaBanacloche J, Keh D, Marshall JC, Parker MM, Ramsay G, Zimmerman JL, Vincent JL, Levy MM (2004) Surviving Sepsis Campaign guidelines for management of severe sepsis and septic shock. Intensive Care Med 30:536-555

11. Dellinger RP, Levy MM, Carlet JM, Bion J, Parker MM, Jaeschke R, Reinhart K, Angus DC, Brun-Buisson C, Beale R, Calandra T, Dhainaut JF, Gerlach H, Harvey M, Marini JJ, Marshall J, Ranieri M, Ramsay G, Sevransky J, Thompson BT, Townsend S, Vender JS, Zimmerman JL, Vincent JL (2008) Surviving Sepsis Campaign: international guidelines for management of severe sepsis and septic shock: 2008. Intensive Care Med 34:17-60

12. Le Gall JR, Lemeshow S, Saulnier F (1993) A new Simplified Acute Physiology Score (SAPS II) based on a European/North American multicenter study. JAMA 270:2957-2963

13. Vincent JL, Moreno R, Takala J, Willatts S, De Mendonça A, Bruining H, Reinhart CK, Suter PM, Thijs LG, on behalf of the Working Group on Sepsis-Related Problems of the European Society of Intensive Care Medicine (1996) The SOFA (Sepsisrelated Organ Failure Assessment) score to describe organ dysfunction/ failure. Intensive Care Med 22:707-710
14. Gayat E, Pirracchio R, Resche-Rigon M, Mebazza A, Mary JY, Porcher R (2010) Propensity scores in intensive care and anaesthesiology literature: a systematic review. Intensive Care Med 36:1993-2003

15. Annane D, Sébille V, Charpentier C, Bollaert PE, Francois B, Korach JM, Capellier G, Cohen Y, Azoulay E, Troché G, Chaumet-Riffaud P, Bellissant E (2002) Effect of treatment with low doses of hydrocortisone and fludrocortisone on mortality in patients with septic shock. JAMA 288:862-871

16. Sprung CL, Annane D, Keh D, Moreno R, Singer M, Freivogel K, Weiss YG, Benbenishty J, Kalenka A, Forst H, Laterre PF, Reinhart K, Cuthbertson $\mathrm{BH}$, Payen D, Briegel J, CORTICUS Study Group (2008) Hydrocortisone therapy for patients with septic shock. N Engl J Med 358:111-124

17. Batalhao ME, Moreto V, Stabile AM, Antunes-Rodrigues J, Carnio EC (2008) Role of dexamethasone on vasopressin release during endotoxemic shock. Regul Pept 147:67-71

18. Bähr V, Franzen N, Oelkers W, Pfeiffer AF, Diederich S (2006) Effect of exogenous glucocorticoid on osmotically stimulated antidiuretic hormone secretion and on water reabsorption. Eur J Endocrinol 155:845-848

19. Gillies GE, Linton EA, Lowry PJ (1982) Corticotrophin releasing activity of the new CRF is potentiated several times by vasopressin. Nature 299:355-357

20. Ertmer C, Bone HG, Morelli A, Van Aken H, Erren M, Lange M, Traber DL, Westphal M (2007) Methylprednisolone reverses vasopressin hyporesponsiveness in ovine endotoxemia. Shock 27:281-288 